\title{
Comparison between Roux-en-Y Gastric Bypass and Mini-gastric Bypass in Patients of Developing Countries
}

\author{
George C Obonna ${ }^{1}$, Martin C Obonna ${ }^{2}$, Rajneesh K Mishra ${ }^{3}$
}

\begin{abstract}
Background: The disease of obesity mostly common in the developed countries is also predominantly seen in the developing countries in recent times. This is therefore a cause to worry.

Aim: To review literature comparing Roux-en-Y gastric bypass (RYGB) and mini-gastric bypass (MGB) to ascertain the more effective and safe bariatric and metabolic operation.

Materials and methods: Detailed literature review online was perfected via Springer Link, International Bariatric Club, and the World Health Organization. Of immense use was a database of 1,000 bariatric surgeries collated from multiple hospitals in the developing countries.

Conclusion: Both bariatric procedures are effective in the treatment of morbid obesity by restriction and malabsorption. They resolve obesityrelated metabolic complications and hence increase quality of life for morbidly obese patients. However, in their comparison, MGB take lesser time to perform than RYGB. Also, MGB has shown to be simpler and safer surgery than RYGB. Thus, in the developing country, with its high population and increasing prevalence of morbidly obese individuals, MGB procedure can be used to treat more patients and also reduce the time and energy taken to manage the patient because of its technical ease, efficacy, revisibility, and reversibility. Overall, a zero mortality in MGB makes it the gold standard in bariatric surgery.

Keywords: Laparoscopy, Mini-gastric bypass, Roux-en-Y gastric bypass.

World Journal of Laparoscopic Surgery (2019): 10.5005/jp-journals-10033-1360
\end{abstract}

\section{INTRODUCTION}

Obesity has become a problem worldwide and currently severely ravaging the developing countries. The developing countries include the recently industrialized countries such as India, China, and many South and Central American countries.

The developed countries such as the Western Europe, Japan, South Korea, Australia, United States, Canada, Israel, and New Zealand have been living in affluence which is highly associated with endemic obesity. The diffusion of western cultural norms has fuelled widespread trends of obesity in developing countries in recent times. Increasing adiposity, improved hygiene and public health services, vaccination and basic amenities, such as safe drinking water, have led to better lifespan long enough to develop problems linked to obesity which included cardiovascular disease and metabolic disorders such as diabetes mellitus, osteoarthritis, and liver cirrhosis. A BMI of 37.5 is classified as severe obesity and surgery remains the weight-reducing gold standard in the treatment of such individuals. Follow-up of these patient is the Achilles' heel of every bariatric program, because in the absence of continuous contact with the patient, the surgeon loses feedback from the patient. Even though some comorbidities of obesity, such as essential hypertension and type 2 diabetes, have been considered in the health bill of the developing countries, obesity itself has not. A few hospitals are trying to perform bariatric surgery in the developing countries; however, this procedure is in direct competition with other digestive system surgeries such as gastric cancer and cholelithiasis, both of which are highly prevalent diseases in the developing country.

This situation means that there are extensive waiting lists for bariatric surgery in the developing countries. The mini-gastric bypass (MGB) which subserves a lesser operating time than Rouxen-Y gastric bypass (RYGB) is thus preferred in this circumstance.
${ }^{1}$ Department of Surgery, University of Medical Science UNIMED Ondo State, Nigeria

${ }^{2}$ College of Medicine, Abia State University, Uturu, Nigeria

${ }^{3}$ World Laparoscopy Hospital, Gurugram, Haryana, India; Department Chair, Minimal Access Surgery, TGO University, India

Corresponding Author: George C Obonna, Department of Surgery, University of Medical Science UNIMED Ondo State, Nigeria, Phone: +2348120206423, e-mail: obogeo2009@yahoo.com

How to cite this article: Obonna GC, Obonna MC, Mishra RK, et al. Comparison between Roux-en-Y Gastric Bypass and Mini-gastric Bypass in Patients of Developing Countries. World J Lap Surg 2019;12(1):29-32.

Source of support: Nil

Conflict of interest: None

Being technically simpler, MGB is a safe and effective alternative to the previous gold standard RYGB with equal results plus the advantage of being technically simpler with lower complication rates and impact more on the quality of life of the patients. ${ }^{1}$

Surgery has become the best treatment for morbid obesity as has been universally accepted. ${ }^{2}$ Both open and minimally invasive laparoscopic surgeries are effective in the management of morbid obesity. ${ }^{3-5}$ Laparoscopy is associated with postoperative complications and requires more operative time and an almost vertical learning curve. ${ }^{6,7}$ Apart from the occurrence of marginal ulcers and reflux bilious gastritis, mini-gastric bypass also known as one anastomosis gastric bypass is easier and adequate enough than Roux-en-Y gastric bypass in the treatment of morbid obesity.

\section{AıM}

The aim is to compare RYGB with MGB with the view of drawing inference on which is best in the treatment of morbid obesity. 
A specified number of bariatric surgeries of RYGB and MGB done were analyzed over several variables.

\section{Materials and Methods}

This a multicenter survey in which there is a detailed review of cases done in specialized hospitals in developing countries assisted by search engines such as MSN, etc., using Springer Link and the Journal of Minimal Access Surgery (MAS). Bariatric-specific longitudinal data analyzed for complication and benefits formed the bedrock of assessment in the comparison of MGB and RYGB.

\section{Operative Techniques}

The MGB (one anastomosis gastric bypass) is a mal-absorption procedure but is also minimally restrictive. Figure 1 depicts the contour of the operation. Robert Rutledge first performed this surgery in $1997 .^{8}$

In laparoscopy, the procedure is done using a five-trocar technique, with the first stapler firing perpendicular to the lesser curvature distal to the crow's foot using a $45-\mathrm{mm}$ green or gold cartridge. Then, a vertical gastric division starting proximally to the left of the angle of His which is not dissected thereby establishing a long gastric tube carved out snugly on a 38-fr bougie. The ostracized part of the stomach remains in situ and extends into a biliopancreatic limb. In the next phase of the procedure, an estimated $200 \mathrm{~cm}$ of the jejunum distal to the ligament of Treitz is where a wide antecolic gastrojejunostomy is done using a $45-\mathrm{mm}$ blue cartridge and closed. The gastrojejunostomy anastomosis may be placed more proximally or distally, depending on the need for weight loss. ${ }^{9}$

Roux-en-Y gastric bypass is principled on restriction and malabsorption. Laparoscopic RYGB was first reported in 1994 by Wittgroove. A small gastric pouch is created by firing the stapler at the level of the second short gastric vessel, straight to the lesser curvature, creating a $30-50 \mathrm{~mL}$ gastric pouch. The jejunum is then transected $50 \mathrm{~cm}$ distal to the ligament of Treitz. The proximal divided end of the jejunum is anastomosed $75 \mathrm{~cm}$ distally (or $150 \mathrm{~cm}$ distally for the superobese), where a stapled side-to-side enteral-enteral anastomosis is done using a $60 \mathrm{~cm}$ white cartridge, with subsequent enterotomy closure. The gastrojejunostomy (Roux $\operatorname{limb}$ ) is done from end-to-end or from end-to-side. This is as shown in Figure $2^{10}$

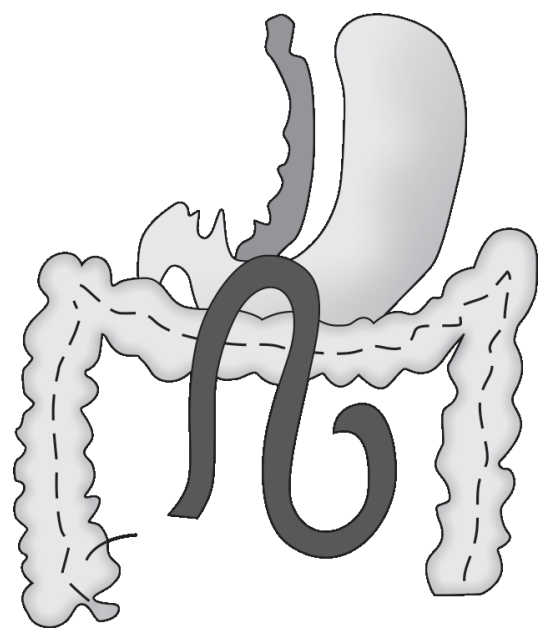

Fig. 1: Showing $M G B^{11}$

\section{Result}

The result was on the parameters of operation time, operative morbidities follow-up, and Quality of Life Assessment survey. A multicenter study of 500 MGBs and 500 RYGB done in 5 years in the developing country revealed the mortality rate to be $0.3 \%$ in RYGB and zero in MGB. A comparative analysis of results is as indicated in Table 1.

Bile reflux was $<1 \%$ in the MGB series and nil in RYGB.

In both, there was no persistent vomiting, and the weight regain was $8.5 \%$ in RYGB but $0 \%$ in MGB.

Hypoalbuminemia was $2 \%$ in RYGB and 13.17 in MGB.

Hypertension, type 2 diabetes, dyslipidemia, and percent excess weight loss had maximum resolution in MGB.

The most common complication of RYGB is leakage which is not seen in MGB. Conversion rate from laparoscopy to open surgery in RYGB ranged $0.8-11.8 \%$. No conversion was recorded after laparoscopic MGB.

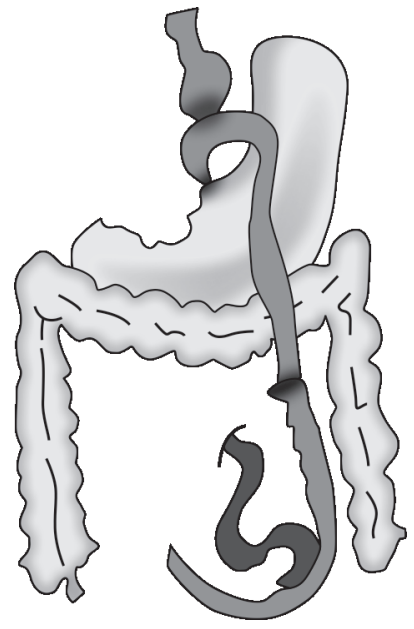

Fig. 2: Showing RYGB ${ }^{11}$

Table 1: Comparative analysis between procedures $(p<0.05)$

\begin{tabular}{lll}
\hline Characteristics & $R Y G B$ & MGB \\
\hline Mortality rate & $0.3 \%$ & 0 \\
Bile reflux & $\mathrm{Nil}$ & $<1 \%$ \\
Persistent vomiting & $\mathrm{Nil}$ & $\mathrm{Nil}$ \\
Weight regain & $8.5 \%$ & $0 \%$ \\
Hypoalbuminemia & $2 \%$ & $13.1 \%$ \\
Duration of operation & $123-198$ minutes & $42-75$ minutes \\
Minor complication & $7.5-15 \%$ & $0-5 \%$ \\
$\quad$ Wound infection & & \\
$\quad$ Gastrointestinal bleeding & & \\
$\quad$ - lleus & & \\
Early anastomotic leakage & $3.3-15 \%$ & $\mathrm{Nil}$ \\
Late anastomotic leakage & $2.2-27 \%$ & $\mathrm{Nil}$ \\
Reoperation rate & $5-10 \%$ & $<1 \%$ \\
Marginal ulcers & $<2 \%$ & $3 \%$ \\
Resolution of hypertension & $72.3 \%$ & $85.4 \%$ \\
Resolution of dyslipidemia & $74 \%$ & $93.3 \%$ \\
Resolution of type 2 diabetes & $75.8 \%$ & $95.1 \%$ \\
Excess weight loss & $72.3 \%$ & $92.2 \%$ \\
\hline
\end{tabular}




\section{Discussion}

It is pertinent to note that previously the more commonly recognized bariatric surgeries are RYGB and vertically banded gastroplasty (VBG). This was enunciated in 1999 by the National Institute of Health Consensus Conference NIH. In 2004, a consensus conference emanated from the American Society for Bariatric Surgery (ASBS), which updated the evidence and the conclusions of the $\mathrm{NIH}$. At this time, RYGB was considered as the most commonly performed bariatric surgery. As the preoperative complications continue to soar, experience became a necessity in the performance of this procedure. Leakage was significant and proved to be the most common complication. ${ }^{11}$ As weight reduction is more in RYGB than in VBG, RYGB became the more popular procedure. Laparoscopic sleeve gastrectomy (LSG) is also another popular technique and has its drawback. The incidence of leaks was even higher in LSG because the intraluminal pressure in the sleeve is very high making the stomach to give way at its weakest point, near the esophagogastric junction.

Mini-gastric bypass is low antecolic and one less anastomosis, and given a better blood supply, it decreases the danger of leakage. High anastomosis near the gastroesophageal junction and the earlier retrocolic method complexes, this procedure and the antecolic approach with a bivalve of the omentum to reduce tension on the mesentery are currently being carried out.

Either way, the technical difficultly and the postoperative complications of leakage, hospital stay, pain, and time taken are more for RYGB compared to MGB. The operative time for RYGB is more than MGB. In laparoscopy, even though five-port technique is used for both, more dissection and anastomosis make RYGB a more time-consuming procedure.

Reflux gastritis does occur in MGB; however, this might require long-term follow-up with endoscopy. The other problem with $M G B$ is the formation of marginal ulcers. Here, the incidence is more compared to RYGB. This is possible because of the volume of gastric tube in MGB. Weight loss and reduction in BM1 is more with MGB compared to RYGB as a result of the long bypass limb of the bowel. This may be associated with nutritional deficiency in folate, hypoalbuminemia, iron, and vitamin..$^{12}$ However, in both, iron deficiency anemia was the only culprit. ${ }^{12-14}$ A long period of follow-up is required to detect the occurrence of micronutrients deficiency and bone diseases. To balance weight reduction with micronutrient deficiency, it is better to adopt the following precautions: use a bypass limb of $150 \mathrm{~cm}$ in those with BM1 less than 40 and add a $10-\mathrm{cm}$ increase in the bypass limb with every BM1 category related to obesity instead of applying a particular $200 \mathrm{~cm}$ limb for all the cases. This will give a better result.

Overall, MGB has a better safety profile than RYGB and is thus preferred. Indications for operation in morbidly obese patients include a BM1 more than 40 or more than 35 if comorbidities are associated.

Note that for patients with moderate obesity BMI 30-35 but suffering with metabolic syndrome, the decreased risk of laparoscopic gastric bypass surgery suggests its inclusion in the options of management.

Maximum resolution of type 2 diabetes, hypertension, and dyslipidemia in the MGB were as a result of the cummulative effect of some restriction of intake, significant rapid transit (incretin effect), and more fat malabsorption. ${ }^{15-20}$ Mini-gastric bypass is proven to be reliable in developing countries like India, as India is only second to China in the population with type 2 diabetes. ${ }^{21,22}$

\section{Conclusion}

In comparing MGB to RYGB in the developing countries, we conclude that MGB is an effective alternative to RYGB. With the increasing burden of obesity in these countries, MGB is a simpler and safer approach toward weight reduction and control of obesity associated metabolic syndrome. With MGB, there is a differential reduction in the short- and long-term complications associated with most other bariatric techniques. It will thus proffer quality treatment to majority of the populace in these recently industrialized developing countries.

\section{References}

1. Karlsson J, Taft C, et al. Ten year trends in health related quality of life after surgical and conventional treatment for severe obesity: the SOS interventional study. Int Jobes 2007;31:1248-1261. DOI: 10.1038/ sj.ijo.0803573.

2. Obonna GC, Obonna MC. NIH conference. Gastrointestinal surgery for severe obesity. Ann Intern Med 1991 Dec 15;115(12):959-961.

3. Wittgrove A, Clark G. Laparoscopicgastric bypass, Roux-en-Y: 500 patients: technique and results, with 3-60 month follow up. Obes Surg 2000 Jun;10(3):233-239.

4. Higa K, Boone K, et al. Laparoscopic Roux-en-Y gastric bypass for morbid obesity. Arch Surg 2000 Sep;139(9):1029-1034. DOI: 10.1001/ archsurg.135.9.1029.

5. Schaver P, Ikranuddin S, et al. Outcomes after Laparoscopic gastric bypass for morbid obesity. Ann Surg 2000 Oct;232(4):515-529. DOI: 10.1097/00000658-200010000-00007.

6. Westling A, Gustavsson S. Laparoscopic vs open Roux-en-Y gastric bypass; a propective randomized trial. Obes Surg 2001 June;11(3):284-292. DOI: 10.1381/096089201321336610.

7. Reddy RM, Riker A, et al. Open Roux-en-Y gastric bypass for the morbidly obese in the era of laparoscopy. Am J Surg 2002 Dec;184(6):611-615. DOI: 10.1016/S0002-9610(02)01090-5.

8. Rutledge R, Walsh W. Continued excellent results with minigastric by pass: six year study in 2,410 patients. Obes Surg 2005;15:1034-1038. DOI: $10.1381 / 0960892054621053$.

9. Lee WJ, Wang W, et al. Laparoscopic mini-gastric bypass: experience with tailored bypass limb according to body weight. Obes Surg 2008;18:294-299. DOI: 10.1007/s11695-007-9367-9.

10. Wittgroove AC, Clerk GW, et al. Laparoscopic gastric bypass, Rouxen-Y Preliminary report of five cases. Obes Surg 1994;4:353-357. DOI: 10.1381/096089294765558331.

11. Wei-Jei L, Po-Juiy RN, et al. Laparoscopic Roux-en-Y vs minigastric bypass for the treatment of morbid obesity: a prospective randomized controlled clinical trial. Ann Surg 2005 July;242(1):20-28. DOI: 10.1097/01.sla.0000167762.46568.98.

12. Brolin RE, Kenler HA, et al. Long limb gastric bypass in the superobes: a prospective randomized study. Ann Surg 1992 Apr;215(4):387-395. DOI: 10.1097/00000658-199204000-00014.

13. Pories WJ, Swanson MS, et al. Who would have thought it? An operation proves to be the most effective therapy for adultonset-diabetes mellitus. Ann Surg 1995 Sept;222(3):339-528. DOI: 10.1097/00000658-199509000-00011.

14. MacLean LD, Rhode BM, et al. Late outcome of isolated gastric bypass. Ann Surg 2000 April;231(4):524-528. DOI: 10.1097/00000658200004000-00011.

15. Bruzz M, Rau C, et al. Single anastomosis or minigastric by pass: Iong term results and quality of life after a 5 year follow up. surg Obes Relat Dis 2015;11:321-326. DOI: 10.1016/j.soard.2014.09.004.

16. Lee W J, Wang W, et al. Effect of laparoscopic minigastric bypass for type 2 diabetes mellitus: comparison of BM1 $>35$ and $<35 \mathrm{~kg} / \mathrm{m}^{2}$. J Gastro intestinal Surg 2000;12:945-952. DOI: 10.1007/s11605-0070319-4.

17. Garciacaballero M, Reyes-ortiz A, et al. Changes of body composition in patients with BMI 23-50 after tailored one anastomosis gastric 
bypass (BAGUA): influence of diabetes and metabolic syndrome. Obes Surg 2014;24:2040-2047. DOI: 10.1007/s11695-014-1288-9.

18. Milone M, Diminno MN, et al. Bariatrcicsurgery and diabetes remission; sleeve gastrectomy or mini-gastric bypass? World Gastreterol 2013;19:6590-6597.

19. Kim Z, Hur KY. Laparoscopic minigastric bypass for type 2 diabetes; the preliminary report. World J Surg 2011;35:631-636. DOI: 10.1007/ s00268-010-0909-2.
20. Guenzi M, Arman G, et al. Remission of type 2 diabetes after omega loopgastric bypass for morbid obesity. Surg Endosc 2015;29:26692674. DOI: 10.1007/s00464-014-3987-7.

21. Kaveesh War SA, Comwall J. The current state of diabetes mellitus in India. Australas Med J 2014;7:45-48. DOI: 10.4066/AMJ.2014.1979.

22. Ding $D$, Chen $D L$, et al. Outcomes after laparoscopic surgery for 219 patients with obesity. Zhonghua Wei Chang Wai ke Zazhi 2011;14(2):128-131. 